\title{
LAS ASPIRACIONES CREATIVAS DE UN COPISTA: LA INTERVENCIÓN DE DIEGO MARTÍNEZ DE MORA EN UN CASTIGO EN TRES VENGANZAS
}

\author{
Francisco Sáez Raposo \\ Instituto de Lengua, Literatura y Antropología \\ Centro de Ciencias Humanas y Sociales (CCHS) \\ Consejo Superior de Investigaciones Científicas (CSIC) \\ C/ Albasanz, 26-28 \\ 28037 Madrid. España \\ francisco.saez@cchs.csic.es
}

[Anuario calderoniano (ISSN: 1888-8046), 3, 2010, pp. 321-332]

De entre la producción dramática de Calderón, la comedia titulada Un castigo en tres venganzas (conocida también como De un castigo, tres venganzas) ha pasado prácticamente desapercibida para la crítica. Compuesta en torno a 1628, según la propuesta basada en criterios métricos de Hilborn ${ }^{1}$ que posteriormente han aceptado, con mayor o menor convicción, Bigelow ${ }^{2}$ y últimamente Cruickshank ${ }^{3}$, su trama se enmarca en el contexto histórico de la corte de Carlos de Borgoña «el Temerario». Modelo del ideal caballeresco a medio camino entre los grandes señores feudales y los príncipes renacentistas, fue el últi-

\footnotetext{
${ }^{1}$ Hilborn, 1938, p. 12.

2 Bigelow, 1975, pp. 93-94.

3 Cruickshank, 2009, pp. 6-8.
} 
mo mandatario de dicha dinastía y uno de los más sobresalientes, ya que durante su gobierno el ducado de Borgoña llegó a su apogeo a través de la expansión territorial y el establecimiento de una nueva ordenación administrativa. El trasfondo político latente en la obra apuntaría directamente hacia la Familia Real española, pues el protagonista había sido bisabuelo del emperador Carlos V.

Su motor argumental gira en torno a su capacidad para administrar justicia ante un caso de traición política. Será su propio enemigo, el Duque de Sajonia, quien le advierta a través de una carta de la deslealtad que con él ha tenido uno de sus hombres de confianza, ya que le ha puesto en aviso del propósito que el de Borgoña tiene de atravesar de incógnito su territorio con el fin de entrevistarse con el Duque de Austria, su sobrino, y acordar una alianza contra el primero. Aunque el conocimiento de dichas intenciones le proporcionaría clara ventaja a la hora de apresarlo y desbaratar sus planes, prefiere, en un acto de suprema caballerosidad, alertar a su enemigo. Es esta prevención la desencadenante de la acción dramática, que se inicia con una interesante escena en la que, intentando desenmascarar al alevoso a través de la reacción que provoca en sus hombres el conocimiento del contenido de la misiva, el Duque realiza un análisis psicológico de ellos. Las respuestas contradictorias, desmesuradas y los enfrentamientos que surgen entre unos súbditos indignados por el suceso y deseosos de evidenciar su lealtad darán al traste con las intenciones de aquel mostrando no tanto la falibilidad e ineficacia del método y, por extensión, de su capacidad como juez, sino la complejidad de una naturaleza humana dificilmente encasillable o predecible. De todos ellos será Clotaldo, quien poco después se desenmascarará como el auténtico traidor, el único que no resulta castigado en este caos inicial e, irónicamente, verá acrecentada la confianza que, como privado, ya tenía, con lo que en sus ansias de ascenso político perderá toda posible competencia que pudieran presentarle los otros tres hombres próximos al Duque: Enrique, su sobrino, Manfredo, quien fuera su ayo y es el padre de la dama Flor, y Federico, súbdito leal que desempeña el papel de galán de la comedia. Este desequilibrio producido en el entramado de relaciones que conforman el círculo de influencia del noble, unido a la animadversión que Clotaldo siente hacia Federico por la relación sentimental que le une a Flor, de la que también está enamorado él, desencadena, aderezado con los celos provocados por 
un enredo en el que están implicados también Clotaldo y Enrique, el segundo asunto de la comedia: el deseo de restitución del honor supuestamente perdido por Federico que irá parejo hasta el final al empeño de reparar su honor de caballero leal a su señor. Justicia, venganza, intrigas palaciegas, anhelos de poder desmedidos e ilícitos, enredos amorosos salpicados con un asesinato, un interés evidente por la caracterización y el análisis psicológico de los personajes, etc., son los componentes de una comedia que, como en su día manifestó Bigelow, parece reclamar una atención algo más detenida que la que se le ha dedicado hasta la fecha ${ }^{4}$.

En los escasos estudios realizados ${ }^{5}$ siempre se ha pasado por alto una de sus singularidades: la existencia de un manuscrito, conservado en la colección de la British Library (Ms. Add.33-472), debido a Diego Martínez de Mora y con algunas enmiendas en los folios finales de mano de Francisco de Rojas. Sólo recientemente, Margaret Greer, en el marco de la edición crítica de la comedia que estamos realizando en colaboración, se ha hecho eco de ello. En la casi veintena de piezas copiadas por el primero que lleva reunidas en su proyecto Manos teatrales ha notado que se trata de un personaje singular y difícil de ubicar en el complejo proceso de transmisión de los textos dramáticos. Mi objetivo será analizar con detalle la labor que Martínez de Mora acometió con la transcripción de este manuscrito concreto y la repercusión que ello ha generado en el texto. Aunque me centraré principalmente en el contraste existente entre el manuscrito y la editio princeps (incluida en la Parte veinte y ocho de comedias de varios autores, Huesca, 1634) $)^{6}$, con el fin de poder obtener resultados significativos al respecto consideraremos también los datos provenientes del cotejo de ellos con las otras cuatro ediciones publicadas durante el siglo XviI: la que vio la luz en la Quinta parte de comedias de D. Pedro

${ }^{4}$ Bigelow, 1975, p. 93.

${ }^{5}$ Ver en la bibliografia final los trabajos de Bigelow y Voros.

${ }^{6}$ Como en su día señaló Profeti (1988, pp. 2, 70-72 y 77-78), la colección se ha conocido con diferentes títulos: Extravagantes, de Afuera, Varios autores y Diferentes. Así, de esta última manera, la denominaré cada vez que me refiera a ella. Para la elaboración de la edición hemos manejado el ejemplar que, con la signatura Ti-30, conserva la Biblioteca Nacional de España. 
Calderón de la Barca, supuestamente publicada en Barcelona en $1677^{7}$ y que tanto criticó el propio dramaturgo, la de la Quinta parte impresa ese mismo año en Madrid, la Novena parte preparada porVera Tassis (Madrid, 1691) y, por último, la otra Novena parte que parece ser una edición contrahecha de comienzos del XVIII pero que apareció también en Madrid con fecha de 1698.

Lo primero que llama la atención es la profusión de didascalias en el manuscrito, ya que hasta en treinta y una ocasiones añade información referente a la representación de la obra de la que adolece la princeps. En la inmensa mayoría de los casos, Martínez de Mora siente la necesidad de aclarar que un parlamento determinado es declamado en aparte por el actor o actriz en cuestión. Quizás su probable actividad como intérprete sirva para explicar esta inclinación y meticulosidad a la hora de señalar este tipo de pasajes. Muy interesado está también en marcar los movimientos escénicos, no sólo en aquellos puntos en los que los otros testimonios no incluyen indicación alguna, sino también cuando, a pesar de que sí lo hacen, añade información adicional con el fin de diferenciar claramente a aquellos personajes que deben abandonar las tablas de los que han de ocuparlas prácticamente de manera simultánea. Así ocurre, por ejemplo, en el verso 1935 cuando a la acotación «Salen el Duque, Clotaldo y gente», que aparece en todos los testimonios referidos, él le antepone la forma verbal «Vase» para indicar una acción de Manfredo que ya había quedado suficientemente evidenciada de manera indirecta a través de sus propias palabras ${ }^{8}$. En este sentido, resulta incluso redundante la didascalia que acompaña al verso 2609, pues Martínez de Mora incorpora al «Salen los dos» que recogen todos los impresos la aclaración «Manfredo y Clotaldo", cuando es algo que resulta obvio pues, precisamente, el Duque acaba de llamarlos a escena y será una intervención de cada uno de ellos la que conforme el verso siguiente. Por su parte, en el 2470 se preocupa por puntualizar que los personajes que abandonan el tablado son Flor y Clotaldo, posiblemente porque estimara que, en un momento en el que éste estaba ocupado por has-

7 Se trata de una edición con pie de imprenta falso, ya que apareció realmente en Madrid. Sirvió de base para la que se publicó en esta ciudad, esta vez sí con los datos de impresión verdaderos, ese mismo año.

8 «Manfredo.- [Aparte] Gente siento. / Por si fuere el duque es bien / irme» (vv. 1933-1935). 
ta cinco actores, un genérico «Vanse» no era lo suficientemente explícito.

Este proceso de (re)escritura que lleva a cabo no se circunscribe, ni mucho menos, a la consignación o la explicitación de multitud de indicaciones escénicas, sino que reflexiona críticamente sobre el texto que está fijando y decide sobre la lectura correcta que debe ofrecer. La collatio del manuscrito y Diferentes arroja un total de 244 variantes entre ambos, de las cuales en 134 ocasiones la lectura del primero es mejor que la del segundo (lo que supone una preeminencia del manuscrito en el $55 \%$ de los casos), en 47 oportunidades ocurre a la inversa (esto significa un 19,3\%), en 48, ambas lecturas son equipolentes $(19,7 \%)$ e, incluso, hay un par de veces en las que los dos presentan una lectura errónea que sólo será enmendada en ediciones posteriores $^{9}$. Finalmente, existen trece casos (es decir, un 5,3\% de las variantes totales que presenta la comedia) en los que uno de los testimonios incluye versos omitidos en el otro. De ellos, sólo en dos oportunidades el balance resulta favorable al impreso.

Aunque sabemos gracias al manuscrito de la obra de Andrés de Claramonte El mayor rey de los reyes que Martínez de Mora era capaz de reproducir de memoria una comedia que hubiera visto representar (destreza, como señala Greer $^{10}$, potenciada por la actividad interpretativa que tal vez desarrollaba por esos años), las variantes que incorpora en su texto parecen no proceder de esta vía, ya que existe un buen número de casos (por ejemplo, los versos 346, 2336, 2350, 2433, etc.) en los que es posible comprobar cómo consigna fielmente la lectura de Diferentes y, sobre ella, tacha y reescribe lo que considera más pertinente. En la cadena de transmisión del texto Martínez de Mora adquiere un papel destacado e incómodo para nosotros, porque no sólo aparece como su mero reproductor, sino que se implica en él y trasciende la pura labor de amanuense a la que probablemente se viera abocado, por el simple hecho de saber leer y escribir, dentro de la compañía teatral a la que perteneciera.

En esa tarea de copista crítico es posible distinguir hasta tres estadios más o menos diferenciados. En primer lugar, realiza correcciones léxicas puntuales correspondientes a erratas evidentes en el texto im-

${ }^{9}$ Son los versos 678 y 1351.

10 Greer, 2008, pp. 205-206. 
preso. Se trata del grupo más nutrido de variantes que existe entre ambos testimonios. Aunque normalmente no es necesario para su localización y enmienda más que de un mínimo de atención ${ }^{11}$, a veces se trata de lecturas menos evidentes desde un punto de vista lingüístico, ya que requieren para su subsanación del conocimiento del contexto en el que se desarrolla la acción dramática. Es lo que sucede en el verso 326, donde el impreso recoge la expresión «recibe para este enfermo" y el manuscrito la correcta "récipe para este enfermo", o en el 483 en el que modifica "Que si a tu honor importó, / no he de detenerle yo» por "Que si a tu honor importó, / no he de detenerte yo», mucho más acorde con la despedida de Flor, consternada, a un Federico que se empeña en encontrar motivo para sus celos en una noticia que le ha dado el gracioso Becoquín, en lugar de sosiego en las sinceras explicaciones de su amada.

Martínez de Mora se percata no sólo de la falta de concordancia gramatical con la que se consignan algunos términos ${ }^{12}$, sino también de las malas atribuciones de parlamentos a ciertos personajes, como sucede en los versos 2411 y 2412 en los que la intervención de Flor está adjudicada a Clotaldo y viceversa, e incluso, en el último de ellos, de una incongruencia con respecto al tratamiento que hasta ese momento se ha venido empleando en la interacción con la dama (mediante la forma gramatical vos), ante lo que decide cambiar la formulación de la pregunta "¿Qué respondes [...]?», que le hace Clotaldo, por la mucho más coherente de «¿Qué respondéis [...]?». Se dan casos, incluso, en los que parece dejarse llevar por el deseo de interpretar pasajes que comportan un planteamiento escénico mucho más sutil, por lo que, ya convertido en una suerte de crítico o director escénico, se adentra por complejos senderos en los que se arriesga a asumir propuestas más imprecisas. Al comienzo de la escena de caza incluida en la segunda jornada, el gracioso Becoquín y Federico escuchan cómo se les acerca el grupo del Duque, por lo que determi-

11 Estaríamos hablando de casos como «me lamo» que aparece en el verso 1288 de Diferentes que el manuscrito corrige en «me llamo», «imsiosibles» [sic] del verso 2048 por «imposibles», «roca fiame» del verso 2192 por «roca firme», "pero tome que el acero» del 2253 por "pero temo que el acero», etc.

${ }^{12}$ El parlamento de Flor, en los versos 2661-2662, en el que declara con sorpresa resignada, tras conocer el presunto fallecimiento de Federico, « $i[\ldots]$ muerto mi bien / y vivo [sic] yo» es corregido pertinentemente. 
nan que lo más conveniente es que Federico se oculte para no ser descubierto en circunstancias tan favorables para la sospecha: escondido en un paraje apartado y vestido en traje de ganapán. Así se declarará justo antes de que aparezca el propio Duque acompañado de Clotaldo:

\begin{tabular}{ll} 
FEDERICO & $\begin{array}{l}\text { Mucho importa, Becoquín, } \\
\text { que aquí no me halle ni vea [el Duque]. } \\
\text { Becóndete entre esas ramas } \\
\text { mientras pasa. }\end{array}$ \\
FEDERICO & \multicolumn{1}{c}{ Aquí te queda } \\
tú por si siente el ruido, \\
y en casa de Celio espera, \\
que hasta allí yo iré seguro. \\
BeCOQuín & Pues retírate que llega. (vv. 1261-1268)
\end{tabular}

El texto es claro a la hora de señalar que es únicamente un personaje, Federico, el que abandona el escenario, sin embargo, Martínez de Mora corrige la forma singular del verbo de la acotación («Escóndese») y la transforma en plural. La aclaración se encuentra sólo unos versos más adelante, cuando el Duque y Clotaldo, que han aparecido súbitamente, se disponen a disparar a ciegas a unos arbustos que se mueven pensando que detrás se agazapa el jabalí que iban persiguiendo y sólo les impedirá hacerlo la terminante exclamación de Becoquín. El Duque muestra su sorpresa al encontrarse con el gracioso:
DUQue
$[\ldots]$ ¿Escondido
que hacéis aquí, soldado?

BeCOQUín

$$
\text { Espulgábame al sol. (vv. 1276-1278) }
$$

La pregunta formulada, que, indudablemente, muestra que los dos personajes no habían visto a Becoquín hasta ese momento, no impli$\mathrm{ca}$, sin embargo, que éste hubiera abandonado el escenario junto a Federico, sino que permanecía oculto a la vista de los otros dos personajes pero no a la del público.

\footnotetext{
${ }^{13}$ La cursiva es mía.
} 
Su propósito de presentar la mejor y más comprensible versión del texto anima al copista a solventar los problemas formales o estructurales que presenta. Así, son cuantiosos los casos en los que no duda en arreglar las irregularidades métricas que encuentra (vv. 556, 573, 1212, 2104 , etc.). Hasta en tres ocasiones (vv. 636, 1688 y 1789) sus ajustes reconstruyen la rima, constituyendo el segundo de los citados el único ejemplo en el que solventa en un mismo verso un descuido métrico y uno de rima a la vez ${ }^{14}$.

Pero sin duda, los casos más interesantes en este procedimiento de reescritura o adaptación dramática son los relativos a la inclusión de variantes e incluso de versos completos inéditos en el resto de testimonios. Podríamos estar, por tanto, en la última fase del proceso, aquella en que el copista da rienda suelta a su faceta puramente creativa.

Las diferencias más relevantes se producen en la parte final de la comedia. En total, el manuscrito aporta 68 versos «nuevos» que, en términos generales, añaden carga trágica a la trama amorosa. Se busca la empatía del auditorio privilegiando este filón temático sobre el estrictamente político. El personaje que centralizará este suplemento trágico en el desarrollo argumental de la obra será el de Flor, convertida en la auténtica víctima de la historia por encima incluso de Federico, que quedará resarcido y reinstaurado en su posición primigenia al final de la historia. El cúmulo de circunstancias arbitrarias e injustas que caracterizan su evolución quedará señalado mediante esas pequeñas adiciones que van forjando una imagen de la dama muy concreta.

La variante más destacable es la correspondiente a una escena completa compuesta por treinta y un versos que aparece añadida en el manuscrito en el tramo final de la comedia, justamente, a partir del 2780. Con ella se pretende pulir la conclusión un tanto brusca que presenta, aportando relevancia a la dama que, extrañamente, desaparece cuando se desmaya tras conocer la noticia del aparente fallecimiento de Federico y ya no se reencontrará con él, como sería de esperar, en la última escena cuando descubrimos que éste únicamente había sufrido un paroxismo causado por un narcótico. En este añadido, Flor

${ }^{14}$ Frente al enunciado «sola de esa razón» que presenta el texto de Diferentes, el manuscrito recoge «sola de esa razón sé» que mantiene, por un lado, la medida octosílaba de la serie en romance a la que pertenece y, por otro, su rima en -é. 
irrumpe con una actitud propia de una verdadera heroína trágica que reclama para sí al Duque, daga en mano, correr la misma suerte que su amado como único modo posible de vindicar la inocencia de éste y la injusticia contra él cometida. El efecto dramático se ve acrecentado porque hace este requerimiento precisamente cuando el gobernante acaba de referir el castigo que ha aplicado a Clotaldo una vez confirmada su responsabilidad en la traición. Su dolor y la grandeza moral que desprende su propósito quedan resaltados por el hecho de que tanto el resto de personajes como el público poseen una información (el desenmascaramiento del traidor y su ajusticiamiento) que ella aún desconoce. El tono trágico que este momento quiere imprimir al personaje y a la obra en general lo explicita la propia Flor cuando, ante el asombro del Duque que, finalmente, deberá interponerse para evitarlo, intenta suicidarse en escena alegando que, de este modo, asistirá a «lo último de mi vida / y el fin de aquesta tragedia» ${ }^{15}$. La reacción, que contrasta notablemente con el carácter y el modo de actuar que ella ha exhibido hasta entonces, se intenta anticipar y justificar unos trescientos cincuenta versos antes cuando, ante la oferta de Clotaldo de anular la condena a muerte de Federico a cambio de aceptar su matrimonio, ella se niega categóricamente. A sus versos de respuesta se agregan en el manuscrito otros cuatro que parecen prepararnos para la voluntad que muestra en la escena final añadida:

15 Reproduzco la escena en su totalidad: «(Sale Flor con una daga en la mano.) Flor.¡Duque [ilegible]! ¡Duque ingrato! / Si tanto crüel, ¿te precias / de justiciero? ¿Por qué / te vengas en la inocencia? / Con esta daga me mata / porque también en mí veas / la muerte como en mi esposo, / o me la daré yo mesma. / Porque, muerto Federico, / no es bien que a su vista vea / Flor sus mismos homicidas, / porque es más que muerte el verlas. / Si le mataste, porque / lo encontraste [Ap. el alma tiembla / en descubrir el secreto] / con Enrique muerto, sepas / que Federico no fue / la causa de esta secreta / desdicha, que de mi padre / lo sabrás [ilegible] en mí veas / la muerte, porque a eso vine, / a buscarte en [ilegible] / para que seáis testigo / y, también, para que veas / lo último de mi vida / y el fin de aquesta tragedia. (Vase a dar y detiénela el Duque.) / Duque.- ¡Tente, Flor! ¡Tente, señora! / Y tu homicida no seas / hasta saberse el engaño, / que yo gustaré lo sepas [verso tachado] / Y tú, Manfredo, comienza». De esta última intervención del Duque existe una primera versión que aparece tachada en el manuscrito. Dice así: «iTente, Flor, tente! No seas / homicida de ti mesma. / Y tú, Manfredo, comienza / a declarar este enredo, / si es bien que el fondo se advierta». 


\author{
[...] Vive Dios, \\ villano, que si el remedio, \\ no digo yo de una vida, \\ pero del mundo, estuviera \\ en que yo bien te quisiera, \\ fuera del mundo homicida \\ $y$ de mí misma, antes que \\ un pensamiento, el más leve, \\ viera en mi amor un aleve \\ traidor, infame $y$ sin $f e^{16}$.
}

Como vemos, la existencia del manuscrito de Martínez de Mora supone un reto a la hora de acometer la edición crítica de la obra. Su concurso en la cadena de transmisión, en un cruce de caminos entre el mero amanuense, el crítico literario y el creador dramático, dificulta su emplazamiento dentro de dicho engranaje y, por consiguiente, la valoración que debemos hacer de su texto, ya que un mayor número de lecturas válidas no implica necesariamente una mayor cercanía al arquetipo.

Esta complejidad es perceptible en casos como el de $A$ secreto agravio, secreta venganza, cuyo manuscrito fue considerado por Wilson ${ }^{17}$ como el texto base sobre el que elaborar su edición mientras que, recientemente, Iglesias Feijoo y Fernández Mosquera han concluido que se trata de un testimonio importante de cara a corregir algunas lecturas erróneas pero nunca predominante con respecto a la princeps.

Así sucede en Un castigo en tres venganzas, pues a lo anteriormente expuesto se suma el excesivo apego con el que Martínez de Mora parece seguir el texto de Diferentes ya que, sobre él, lleva a cabo las modificaciones que considera oportunas. Ni siquiera los quince versos de éste (desde el 100 hasta el $113^{18}$ y el 2745) ausentes en el ma-

16 Se trata de los vv. 2421-2426 y los cuatro versos que el manuscrito añade después de este último (señalados en cursiva) y que no he numerado con respecto al conjunto de la comedia.

17 Wilson, 1958, pp. 72-73. Es necesario señalar que, quizás en la consideración de Wilson, influyera el hecho de que en un principio creyó que el manuscrito de Martínez de Mora era, en realidad, el autógrafo de Calderón.

${ }^{18}$ Sobre estos versos en concreto, afirma Greer que, por el lugar que ocupan en la comedia y por el desequilibrio estructural que causa su omisión, «seguramente son de Calderón» (ver Greer, 2008, p. 203). 
nuscrito invalidarían nuestra hipótesis, pues ello también respondería al proceso de adaptación del texto a una circunstancia de representación específica. Por consiguiente, todo parece indicar, según los datos con los que contamos, que el término post quem para fechar este testimonio es el año 1634, en el que la obra vio la luz en forma impresa por vez primera. El hecho de que Martínez de Mora no califique este manuscrito como "original», práctica que siguió en aquellos que preparó mientras estuvo vigente la prohibición de imprimir comedias en Castilla (1625-1634), apunta también en esa dirección. Asimismo, la existencia de signos de puntuación que remedan los que aparecen en el impreso descarta su proveniencia de otro manuscrito anterior a la princeps que hubiera podido ser incluso el autógrafo que perteneciera a la compañía teatral para la que trabajara.

Martínez de Mora actúa sobre el texto calderoniano de tal manera que no sólo quiere formar parte de la urdimbre propia de su difusión, sino, además, de la (re)creación del mismo, definiéndose, desde ese momento, como parte activa de ese proceso de producción de nuestro teatro áureo que fue el fenómeno de la reescritura, entendido en su sentido más amplio, aún hoy considerado como una cuestión compleja, heterogénea, globalizadora y tendente al prejuicio. 


\section{Bibliografía}

Bigelow, G. E., «A Note on the Date and Editions of Calderón's De un castigo, tres venganzas», Estudios Ibero-Americanos, 1, 1975, pp. 93-101.

- «Analysis of Calderon's De un castigo, tres venganzas: Structure, Theme, Language», Critical Perspectives on Calderón de la Barca, dirs. F. A. De Armas, D. M. Gitlitz y J. A. Madrigal, Lincoln, Society of Spanish and SpanishAmerican Studies, 1981, pp. 13-37.

- "De un castigo, tres venganzas y la coincidencia de justicia y venganza en el teatro de Calderón», Calderón. Actas del "Congreso internacional sobre Calderón y el teatro español del Siglo de Oro, ed. L. García Lorenzo, Madrid, CSIC, 1983, vol. II, pp. 827-838.

Cruickshank, D. W., Don Pedro Calderón, Cambridge, Cambridge University Press, 2009.

Greer, M. R., «La mano del copista: Diego Martínez de Mora interpreta a Calderón", Anuario calderoniano, 1, 2008, pp. 201-221.

Hilborn, H. W., A Chronology of the Plays of D. Pedro Calderón de la Barca, Toronto, The University of Toronto Press, 1938.

Profeti, M. G., La collezione "Diferentes autores», Kassel, Reichenberger, 1988.

Voros, S. D., «Feminine Symbols of Empire in Thomas Kyd and Pedro Calderón: The Spanish Tragedy and De un castigo tres venganzas», Pacific Coast Philology, 27, 1-2, pp. 145-158.

Wilson, E. M., "Notes on the Texts of $A$ secreto agravio, secreta venganza», Bulletin of Hispanic Studies, 35, 1958, pp. 72-82. 